\title{
Airway function in infancy is linked to airflow measurements and respiratory symptoms from childhood into adulthood
}

\author{
Authors: Louisa Owens $\mathrm{MB}^{1,2}$, Ingrid A. Laing $\mathrm{PhD}^{3,4}$, Guicheng Zhang \\ $\mathrm{PhD}^{5,6}$, Steve Turner $\mathrm{MD}^{7}$, Peter N. Le Souëf $\mathrm{MD}^{1}$ \\ ${ }^{1}$ School of Medicine University of Western Australia, GPO Box D184, Perth, Australia \\ ${ }^{2}$ School of Women's and Children's Health, University of New South Wales 2031, Australia \\ ${ }^{3}$ Telethon Kids Institute, 100 Roberts Road, Subiaco, Western Australia 6008, Australia \\ ${ }^{4}$ School of Biomedical Sciences, University of Western Australia, GPO Box D184, Perth, \\ Australia \\ ${ }^{5}$ School of Public Health, Curtin University, Bentley, Western Australia 6845, Australia \\ ${ }^{6}$ Centre for Genetic Origins of Health and Disease, University of Western Australia and \\ Curtin University \\ ${ }^{7}$ School of Medical Sciences, University of Aberdeen, AB24 3FX, Scotland
}

Corresponding Author: Dr Louisa Owens

Email: louisa.owens@health.nsw.gov.au

Phone: 0293821477

Address: Level 4, Sydney Children's Hospital, High Street, Randwick, NSW 2031, Australia

\section{Funding:}

NHMRC Research grant APP1031635; Princess Margaret Hospital Foundation

Seeding Grant 9383; University of Western Australia PhD scholarship; Asthma Foundation of Western Australia PhD top-up scholarship

\section{Keywords:}

Infant lung function; longitudinal birth cohort; spirometry; asthma

\section{Running Title:}

Infant lung function predicts adult airway function 


\section{Abstract:}

Introduction: Increasing evidence suggests that poor lung function in adulthood is determined very early in life. Our study aims were: (1) identify factors associated with early infant lung function; (2) quantify the link between early infant lung function and early adult lung function; (3) identify environmental and inherited factors which predict lung function throughout the post-natal growth period.

Methods: In this longitudinal study, 253 individuals were recruited antenatally. Lung function and allergy testing occurred at 1, 6, 12 months, 6, 11, 18 and 24 years of age. The relationship between lung function at 1 month (V'maxFRC) and spirometry variables at each follow-up was evaluated. Early life predictors of spirometry were assessed longitudinally using linear mixed models.

Results: V'maxFRC correlated positively with FEF25-75\% at every assessment from 6 to 24 years and $\mathrm{FEV} / \mathrm{FVC}$ at 11 and 24 years and inversely with airway responsiveness at 6 and 18 years. Maternal asthma and smoking in pregnancy were associated with lower FEV from $^{6}$ to 24 years $(-99 \mathrm{ml}, \mathrm{p}=0.03 ;-77 \mathrm{ml}, \mathrm{p}=0.045$ respectively). Lower V'maxFRC at 1 month was associated with asthma and wheeze through to 24 years.

Conclusion: Lung airflow measurements track from birth into early adulthood, suggesting a permanent and stable airway framework is laid down in the antenatal period. Lower infant airway function is associated with respiratory symptoms into adulthood, indicating the link is clinically important. Antenatal and early life exposures must be addressed in order to maximise airway growth and reduce lifelong respiratory compromise. 


\section{Abbreviations:}

COPD - chronic obstructive pulmonary disease

DRS - dose response slope

FEF25-75\% - forced expiratory flow rate between $25-75 \%$ of forced vital capacity

FEV1 -forced expiratory volume in 1 second

FVC - forced vital capacity

Log - natural logarithm

PIAF - Perth Infant Asthma Follow up study

V'maxFRC - Maximum flow rate at functional residual capacity 


\section{Introduction:}

The lungs mature throughout life, from development of the lung architecture in utero, airway and parenchymal growth in childhood and adolescence, through to degenerative changes during adulthood. Spirometry is a surrogate measure of both airway calibre and lung growth and the changes in the development of these with age are reflected in lung function testing ${ }^{1}$. Increasing evidence shows that determinants of poor lung function and respiratory disease in adulthood are active in very early life ${ }^{2-7}$.

Both males and females reach their peak lung function in early adulthood, making this an ideal time to assess total lung growth ${ }^{1}$. The antenatal, early life and genetic factors that affect this peak in lung function will likely impact on function through to late adulthood. Reduced lung function in early adulthood is associated with chronic obstructive pulmonary disease (COPD) in later life ${ }^{8}$, emphasising the importance of attaining maximum lung growth prior to the inevitable decline. Identifying in utero, genetic and environmental factors which affect growth in lung function from early infancy, throughout childhood and into adulthood, has the potential to lead to interventions that ensure maximum lung growth is attained, thus leading to improved lifelong lung health.

In the Tucson longitudinal respiratory birth cohort study, those with low lung function in infancy continued to have low lung function into adulthood ${ }^{9}$. Despite the importance of this finding, the study's results have not been replicated given the several decades of follow-up necessary and the difficulties in performing infant lung function testing which was a relatively new technique 30 years ago ${ }^{9}$.

In our cohort, infants' lung function was studied very early, at one month of age when minimal effect of post-natal exposures would be expected, and was repeated during infancy at 6 and 12 months. Spirometry was performed by the cohort at follow-up assessments every 6 years 
between the ages of 6 and 24 years of age. We hypothesised that both lung function at one month and post-natal environmental exposures are important in determining the peak lung function reached by young adults. The aims of our study were to (1) identify the factors associated with lung function measured soon after birth, (2) assess the link between lung function at 1 month of age and lung function in early adulthood and (3) identify environmental and inherited factors that predict lung function throughout the post-natal growth period, between 1 month and 24 years.

\section{Materials and Methods:}

The Perth Infant Asthma Follow up study (PIAF) is a longitudinal birth cohort with 253 individuals recruited antenatally from a suburban maternity hospital between 1987 and 1990 . There was no pre-selection based on family history of asthma or atopy. Recruitment has been described in detail previously. ${ }^{10}$

These subjects have had detailed respiratory assessments at 1, 6, 12 months, 6, 11, 18 and 24 years of age, including questionnaires, lung function, airway responsiveness and skin prick testing.

Infant lung function testing at 1, 6 and 12 months of age involved rapid thoraco-abdominal compression during tidal breathing at the end of normal inspiration, after sleep was induced with oral chloral hydrate. ${ }^{11} \mathrm{~V}$ 'maxFRC, the maximum flow at functional residual capacity, was recorded as the mean of 3-5 acceptable measurements. Infant lung function data were not reported as percent predicted according to our laboratory's reference equation, as this equation adjusts for sex and adjusted for sex and in utero smoke exposure ${ }^{12}$. 
Spirometry, using dynamic forced expiratory flow manoeuvre at 6, 11, 18 and 24 years, measured forced expiratory volume in 1 second $\left(\mathrm{FEV}_{1}\right)$, forced vital capacity $(\mathrm{FVC})$, forced expiratory flow between $25-75 \%$ of FVC (FEF25-75\%) and $\mathrm{FEV}_{1} / \mathrm{FVC}^{13}$.

Airway responsiveness was assessed at 1 month of age with a histamine challenge using handheld glass dosimeters and the Yan technique ${ }^{14}$. Increasing concentrations of histamine were inhaled until a drop in V'maxFRC of $40 \%$ was reached, signifying a positive test. Those with a negative airway responsiveness challenge did not reach a 40\% drop in V'maxFRC despite inhaling the maximum cumulative dose of $7.8 \mu \mathrm{mol}$ of histamine. The dose response slope (DRS) is the maximum percentage drop in V'maxFRC divided by the cumulative dose of inhaled histamine ${ }^{15}$.

Skin prick testing was carried out at 1, 6 and 12 months of age to rye grass pollen, cow's milk, egg white, Dermatophagoides pteronyssinus and D. farinae ${ }^{16,17}$. A mean wheal diameter of $\geq 3 \mathrm{~mm}$ greater than the control was recorded as positive. Only those with a positive result or those who were assessed at all three time points $(n=179)$ were included in the analysis, as a positive test could not be ruled out otherwise.

Antenatal and infant questionnaires were completed by one or both parents at each assessment and included: questions regarding current and previous smoking history and current and previous feeding history including breastfeeding history and timing of introduction of breastmilk substitute formula. Only those with complete feeding history were included in the analysis of breastfeeding $(\mathrm{n}=181)$.

Questionnaires from 6 years of age were completed by the parent or participant as appropriate. Recent wheeze at each assessment was defined by symptoms in the previous 12 months. Current asthma at each assessment was defined by a physician diagnosis, plus symptoms or asthma medications within the previous 12 months. 
Predictive variables were chosen based on known associations with lung function in infancy or childhood and included: sex; exposure to tobacco smoke in utero; parental history of asthma; birthweight; exclusive breastfeeding the first three months in infancy; infant atopy (a positive skin prick testing at 1, 6 or 12 months of age); physician diagnosis asthma during childhood; smoking.

The study was approved by the Princess Margaret Hospital for Children Ethics Committee (2054EP). Parents or subjects when appropriate, signed informed consent forms for each assessment.

\section{Statistics}

Factors associated with V'maxFRC at 1 month were identified using the General Linear Model. Each potential factor was entered into the model separately. Infant length at time of assessment was included and the mean V'maxFRC for each group was standardised to the mean length of the infants. All significant variables from the univariate model were then included in a multivariate model, including interaction terms.

The association between lung function at 1 month and at subsequent follow-ups was assessed with Pearson's correlation (r) or Spearman's correlation $(\rho)$ for non-parametric variables. $\mathrm{R}^{2}$ estimated the $\%$ variability in spirometry measurements accounted for by infant lung function. V'maxFRC at 1 month was log transformed (base e) to approach a normal distribution and then adjusted for concurrent length. Dose response slope from histamine challenge was also log transformed. Spirometry variables were adjusted for sex and concurrent height at each assessment.

Linear mixed models were used to assess the link between early life factors and spirometry outcomes longitudinally, in the context of known infant lung function, using unstructured covariance. Spirometry variables from each assessment at 6, 11, 18 and 24 years were included 
in the model. Time-dependent factors, age and height at each assessment, were included in the model and sex was included as a time-independent factor. Each predictive variable was entered into the model separately and then significant factors were all included in a multi-variate model. V'maxFRC was again logarithmically transformed and adjusted for length.

Lung function at 1 month of age as a predictor of recent wheeze and current asthma at each follow-up was assessed with logistic regression and odds ratios are reported. Post-hoc analysis included current atopy as a co-factor in the model, as defined by positive skin prick test. V'maxFRC at 1 month was log transformed, adjusted for length and divided into two groups, about the median. Mean spirometry variables at each assessment were calculated for these two groups, having adjusted for concurrent height, age and sex and standardised to the mean height and age, using a general linear model. This is portrayed graphically.

A 2-sided $\mathrm{p}$ value $<0.05$ was used to define statistical significance. Statistical analyses were performed using IBM SPSS Statistics for Windows, version 24·0·0 (Released 2016, Armonk, NY: IBM Corp.) 


\section{Results:}

\section{Baseline Data}

Of the original cohort, 242 participants had infant lung function testing at 1 month of age, 195 at 6 months and 165 at 12 months. Of those assessed at 1 month, 190 were seen for follow up at least once at $6,11,18$ or 24 years and were included in longitudinal analysis. Participation numbers and characteristics at each follow up have been presented previously ${ }^{24}$. There was less maternal in utero smoke exposure in the group seen at 18 and 24 years (25\%), than in the original cohort (32\%). Unadjusted baseline spirometry at each assessment is presented in supplementary table 1.

\section{Lung function during infancy}

Mean V'maxFRC doubled in the first year of life from $98.9 \mathrm{ml} / \mathrm{sec}$ (SD 49.6) at 1 month, to $157.2 \mathrm{ml} / \mathrm{sec}(\mathrm{SD} \mathrm{71})$ at 6 months and $200.1 \mathrm{ml} / \mathrm{sec}(\mathrm{SD} 82.8)$ at 12 months of age. Lung growth tracked throughout infancy with a strong correlation between V'maxFRC at 1 month and 6 months $(\rho=0.55, p<0.001)$ and V'maxFRC at 6 months and 12 months of age $(\rho=0.45$, $\mathrm{p}<0.001)$.

\section{Predictors of lung function at 1 month of age}

Male gender was associated with lower lung function at 1 month of age (mean V'maxFRC: males $92.0 \mathrm{ml} / \mathrm{sec}$ and females $107.3 \mathrm{ml} / \mathrm{sec}, \mathrm{p}=0 \cdot 019)$. Exposure to maternal tobacco smoke in utero was associated with lower infant lung function at 1 month (mean V'maxFRC: 89.4 $\mathrm{ml} / \mathrm{sec}$ if exposed and $104.4 \mathrm{ml} / \mathrm{sec}$ if not exposed, $\mathrm{p}=0.027)$. Birthweight, parental asthma, paternal smoking during the pregnancy and infant atopy were not associated with a significant difference in lung function at 1 month of age (table 1$)$. 
In the multivariate model, sex $(\mathrm{p}=0.044)$ and maternal in utero smoking $(\mathrm{p}=0.022)$ were independently associated with V'maxFRC at 1 month of age. There was no significant interaction effect between sex and maternal smoking on infant lung function $(\mathrm{p}=0 \cdot 576)$.

\section{Tracking of lung function from 1 month to 24 years}

V'maxFRC at 1 month correlated with FEF25-75\% at each assessment from 6 to 24 years and with $\mathrm{FEV}_{1} / \mathrm{FVC}$ at 11 and 24 years (supplementary table 2 ). $\mathrm{R}^{2}$ ranged from 0.03 to $0 \cdot 08$, thus V'maxFRC at 1 month accounted for up to $8 \%$ of the variability in FEF $25-75 \%$ and $\mathrm{FEV}_{1} / \mathrm{FVC}$ at each follow up assessment.

V'maxFRC was inversely correlated with airway responsiveness, as measured by the dose response slope in histamine challenge, at 6 and 18 years $(r=-0.25 p=0.013$ and $r=-0.22$ $\mathrm{p}=0 \cdot 016$ respectively. Supplementary table 2 ).

\section{Infant airway responsiveness and spirometry at each follow up}

Infant airway responsiveness at 1 month of age, as measured by the DRS to histamine challenge, was significantly correlated with $\mathrm{FEV}_{1}$ and $\mathrm{FVC}$ at 6 years of age $(\mathrm{r}=-0.225$, $\mathrm{p}=0.039 ; \mathrm{r}=-0.338, \mathrm{p}=0.002$ respectively), but not at further assessments between 11 and 24 years of age. There was no link between V'maxFRC and DRS at 1 month (supplementary table $3)$. 


\section{Longitudinal analysis of lung function}

Amongst those with infant lung function measurements at 1 month of age, 190 participants had 525 follow-up lung function assessments at 6, 11, 18 and/or 24 years. In longitudinal analysis, V'maxFRC at 1 month was positively associated with FEF25-75\% and $\mathrm{FEV}_{1} / \mathrm{FVC}$ from 6-24 years. Exposure to maternal smoking in utero was associated with lower $\mathrm{FEV}_{1}$ from 6-24 years compared with those not exposed (mean difference $-0.085 \mathrm{~L}, \mathrm{p}=0 \cdot 048$ ). A history of physician diagnosed asthma was associated with lower $\mathrm{FEV}_{1} / \mathrm{FVC}$ from 6 to 24 years compared with those with no history of asthma (mean difference $-3 \cdot 1 \%, \mathrm{p}=0 \cdot 001$ ). A positive skin prick test in the first year was associated with lower $\mathrm{FEV}_{1}, \mathrm{FEF} 25-75 \%$ and $\mathrm{FEV}_{1} / \mathrm{FVC}$ from 6 to 24 years compared with those with no positive skin prick tests during infancy (mean difference $0.138 \mathrm{~L} \mathrm{p}=0 \cdot 018,-0 \cdot 298 \mathrm{~L} / \mathrm{s} \mathrm{p}=0 \cdot 006 \mathrm{~L} / \mathrm{s}$ and $-2 \cdot 3 \% \mathrm{p}=0 \cdot 034$, respectively). Current tobacco smoking at 24 years of age was not associated with any lung function variable from 6 to 24 to years. Table 2.

Only variables with a significant relationship in the univariate analysis $(\mathrm{p}<0 \cdot 05)$ were included in multivariate analysis. V'maxFRC at 1 month was associated with FEF25-75\% from 6 to 24 years in the multivariate analysis and infant atopy was associated with $\mathrm{FEV}_{1}, \mathrm{FEF} 25-75 \%$ and $\mathrm{FEV}_{1} / \mathrm{FVC}$ from 6 to 24 years (table 3 ).

\section{Longitudinal lung function and V'maxFRC below and above median}

Using Linear Mixed Models, including sex, age and height in the model, V'maxFRC above the median at 1 month was associated with significantly higher FEF25-75\% from 6 to 24 years (mean difference $0 \cdot 22 \mathrm{~L} / \mathrm{s}, \mathrm{p}=0 \cdot 001$ ) and $\mathrm{FEV}_{1} / \mathrm{FVC}$ longitudinally from $6-24$ years (mean 
difference $2.46 \% \mathrm{p}=0 \cdot 002$ ). There was no significant association with $\mathrm{FEV}_{1}$ or FVC. The mean lung function at each assessment are depicted in figure 1.

\section{V'maxFRC predicts wheeze and asthma}

Participants with a V'maxFRC below the median at 1 month of age were more likely to have had recent wheeze within the previous 12 months at 6,11 and 24 years, than those with V'maxFRC above the median.

Participants with a V'maxFRC below the median at 1 month of age were more likely to have asthma in the previous 12 months at 18 and 24 years, than those with V'maxFRC above the median (table 4). These associations remained significant when adjusted for current atopy (OR $=4 \cdot 3, \mathrm{p}=0 \cdot 013$ at 18 years and $\mathrm{OR}=5 \cdot 5, \mathrm{p}=0 \cdot 009$ at 24 years $)$. 


\section{Discussion:}

Our study establishes that the principal influence of impaired infant lung function on respiratory function in early adulthood is on airflow, as measured by $\mathrm{FEV}_{1} / \mathrm{FVC}$ and FEF25$75 \%$, rather than overall lung size, as measured by $\mathrm{FEV}_{1}$ and FVC. We have also demonstrated that low lung function in early infancy is associated with respiratory symptoms throughout childhood and into early adulthood. The clearly separate relationships between infant V'maxFRC (a flow-related variable) and flow-related spirometric variables in adulthood, as opposed to variables more greatly influenced by lung size, have not been previously demonstrated. There is likely a causal relationship between the development of relatively abnormal airway physiology antenatally and the clinical outcomes related to airway calibre, wheeze and asthma, which persist throughout the post-natal lung growth period.

Our findings are in line with prior reports, including those from the Tucson Children's Respiratory Study ${ }^{9}$, that have found infant lung function to be related to reduced lung function in early adulthood, however previous studies did not demonstrate an association specifically with variables that reflect airway function. Infant lung function in our cohort was measured in a larger number of subjects and closer to birth with a tightly controlled age and hence less likely to be influenced by environmental factors. Physiologically, the strength of our current data, when considered alongside data from previous analyses ${ }^{9,18}$, suggest that future airway structure is laid down in the antenatal period, but that this is separate from the potential for lung growth, which is also known to be influenced by antenatal and early life exposures.

V'maxFRC at 1 month of age was inversely associated with airway responsiveness at 6 and 18 years. That is, those with higher lung function in infancy, had lower airway responsiveness 
later on and vice versa. Increased airway responsiveness, sensitivity of the airways, is one of the hallmarks of asthma and correlates with symptom severity. Airway responsiveness is related to inflammation of the lower airways ${ }^{19}$ and airway inflammation is associated with reduced airflow. As we did not take airway samples, we could not assess for the presence or degree of airway inflammation. A previous publication from the 6 year follow-up of the PIAF cohort, showed that increased airway responsiveness during infancy was associated with lower lung function in early childhood ${ }^{20}$. However in subsequent assessments, this association is no longer seen, suggesting that infant airway responsiveness and the presumed underlying inflammation, is not a permanent change.

A number of factors were identified which were associated with lung function at just 1 month of age. Exposure to maternal in utero tobacco smoking and male gender were both independently associated with lower V'maxFRC at 1 month. These findings have previously been reported in the PIAF cohort, albeit when looking at repeated measurements throughout the first year of life, as well as in studies by other groups ${ }^{12,21,22}$. We assume that lung function at 1 month of age is reflective of antenatal growth. Only term infants were included and this first assessment was performed before the infants' had any significant respiratory illnesses but there would have been some environmental exposures, such as exposure to tobacco smoke in the home, feeding (breastmilk versus formula) and aeroallergen exposure (house dust mite, animal dander, pollens etc.), which could potentially have had some impact on lung function in the neonatal period.

In utero tobacco smoke exposure was associated with lower infant lung function at 1 month of age as well as lower $\mathrm{FEV}_{1}$ throughout childhood up to early adulthood. This subtle deficit, 
mean $77 \mathrm{ml}$, may be of long-term clinical significance given that a lower $\mathrm{FEV}_{1}$ in early adulthood is associated with increased risk of COPD as well as all-cause mortality ${ }^{23,24}$.

In this cohort, those with a history of asthma during childhood had persistently lower $\mathrm{FEV}_{1} / \mathrm{FVC}$ throughout childhood up to early adulthood, while a history of maternal asthma was associated with lower $\mathrm{FEV}_{1}$. Asthma in early adulthood is associated with lower infant lung function at 1 month and reduced flow throughout childhood ${ }^{25}$. Low $\mathrm{FEV}_{1} / \mathrm{FVC}$ is a defining criteria of COPD and these results support the hypothesis that childhood asthma is a risk factor for $\mathrm{COPD}^{26}$. The association between early atopy and lower lung function from infancy into early adulthood has previously been reported in this cohort ${ }^{18,25}$. The effect of children smoking tobacco themselves during childhood and adolescence on lung function was not addressed in this study, as parents were present at the assessments up until 18 years of age and thus a truthful answer could not be assumed. Therefore only tobacco smoking at 24 years was included in the model and so we are unable to comment on the effect of self-smoking on the developing lung.

This study has a number of limitations which are inevitable due to the length of follow up. Firstly, the technique for measuring infant lung function which was used in this study is based on the tidal volume range and was the standard in the late 1980s when this study began. This technique has since been adapted to more closely mimic spirometry using raised volume ${ }^{27,28}$. However, we still found significant correlations between the infant lung function measurement, V'maxFRC and spirometry variables, particularly FEF25-75\%, which is also a measure of airflow at low lung volume. Total infant lung capacity measurements would have been interesting, but measuring this in addition to the technique used would have been impractical. Furthermore, infant lung function testing is a very labour and time intensive procedure, making 
the recruitment of large cohorts almost impossible. Given that this study has spanned almost three decades, a loss to follow up is not unexpected. Perth, Western Australia is a particularly isolated city and many young people travel for work, college or leisure in their early adult years, which may have contributed to the difficulty in retaining participation. By using mixed models, we were able to compensate for missing values in those who had multiple follow ups.

Another limitation to note is that lung function was performed without bronchodilator responsiveness, therefore reversibility was not assessed. However in another longitudinal respiratory birth cohort study, there was no significant difference in relationships between pre and post bronchodilator values at follow ups and infant lung function 9 .

Lung airflow measurements track from soon after birth into early adulthood, indicating a permanent and stable airway framework, which is laid down in the antenatal period. Lower airway function in infancy is associated with respiratory symptoms through into adulthood, signifying a clinically significant effect. Antenatal factors, particularly tobacco smoke exposure, must continue to be addressed in order to maximise lung function into early adulthood and thus reduce the risk for lifelong respiratory compromise.

\section{Conflict of interest statement}

The Authors have no conflict of interest to declare with regards to this manuscript.

\section{Acknowledgments:}

We would like to thank all the previous contributors to the Perth Infant Asthma Follow up study including David Mullane, Desmond Cox, Kimberley Franks, Lou Landau, Jack Goldblatt, Sally Young, Siew-Kim Khoo, Neil Gibson, Veena Judge, Lyle Palmer, Paul O'Keefe, Jackie Arnott, Steve Stick and Peter Rye. 
Table 1. Factors associated with lung function at 1 month of age: Univariate model

\begin{tabular}{|c|c|c|c|c|c|}
\hline & & $\mathbf{N}$ & $\begin{array}{c}\text { Mean V'maxFRC } \\
\mathrm{ml} / \mathrm{sec}\end{array}$ & $95 \% \mathrm{CI}$ & p value \\
\hline \multirow[t]{2}{*}{ Sex } & Male & 134 & 91.98 & $83 \cdot 52-100 \cdot 45$ & 0.019 \\
\hline & Female & 108 & $107 \cdot 27$ & $97 \cdot 82-116 \cdot 72$ & \\
\hline \multirow[t]{2}{*}{ Maternal Asthma } & No & 192 & $98 \cdot 88$ & $91 \cdot 79-105.98$ & 0.96 \\
\hline & Yes & 50 & $98 \cdot 5$ & $84 \cdot 58-112 \cdot 43$ & \\
\hline \multirow[t]{2}{*}{ Paternal asthma } & No & 197 & $103 \cdot 15$ & $92 \cdot 89-107 \cdot 01$ & 0.34 \\
\hline & Yes & 34 & $93 \cdot 75$ & $75.92-109.97$ & \\
\hline \multirow[t]{2}{*}{ Maternal smoking in pregnancy } & No & 157 & $104 \cdot 37$ & $96 \cdot 59-112 \cdot 14$ & 0.027 \\
\hline & Yes & 84 & $89 \cdot 38$ & $78 \cdot 71-100 \cdot 05$ & \\
\hline \multirow[t]{2}{*}{ Paternal smoking in pregnancy } & No & 141 & $90 \cdot 1$ & $94 \cdot 76-111 \cdot 55$ & $0 \cdot 17$ \\
\hline & Yes & 88 & $82 \cdot 27$ & $83 \cdot 41-104 \cdot 1$ & \\
\hline \multirow[t]{4}{*}{ Birthweight } & $<3000 \mathrm{~g}$ & 43 & $85 \cdot 04$ & $69 \cdot 45-100 \cdot 64$ & $0 \cdot 276$ \\
\hline & $3000-3500 \mathrm{~g}$ & 97 & $102 \cdot 59$ & $92 \cdot 56-112.63$ & \\
\hline & $3500-4000 \mathrm{~g}$ & 72 & $101 \cdot 48$ & $89 \cdot 68-113 \cdot 27$ & \\
\hline & $>4000 \mathrm{~g}$ & 27 & $103 \cdot 22$ & $83 \cdot 72-112 \cdot 73$ & \\
\hline \multirow[t]{2}{*}{ Early atopy } & No & 138 & $103 \cdot 62$ & $94 \cdot 97-112 \cdot 27$ & 0.093 \\
\hline & Yes & 31 & $86 \cdot 26$ & $67 \cdot 9-104 \cdot 56$ & \\
\hline
\end{tabular}

V'maxFRC at 1 month was adjusted for length and then standardised to mean length of the infants at 1 month $(=55.1 \mathrm{~cm}) .95 \%$ CI confidence intervals. Bold font indicates $\mathrm{p}<0 \cdot 05$. Parental asthma ever at time of recruitment. Parental smoking at all during the pregnancy. Early atopy -positive skin prick test in first year of life. 
Table 2. Associations with lung function longitudinally from 6 to 24 years: univariate analysis

\begin{tabular}{|c|c|c|c|c|c|c|c|c|c|}
\hline \multicolumn{2}{|c|}{$\begin{array}{c}\text { No. of subjects } \\
\text { included } \\
\text { (no. of assessments) }\end{array}$} & \multicolumn{2}{|c|}{$\begin{array}{l}\text { Mean difference in } \\
\operatorname{FEV}_{1}(\mathrm{~L}) \\
(6-24 \text { years })\end{array}$} & \multicolumn{2}{|c|}{$\begin{array}{c}\text { Mean difference in } \\
\text { FVC }(\mathrm{L}) \\
(6-24 \text { years })\end{array}$} & \multicolumn{2}{|c|}{$\begin{array}{l}\text { Mean difference in } \\
\text { FEF25-75\% }(\mathrm{L} / \mathrm{s}) \\
(6-24 \text { years })\end{array}$} & \multicolumn{2}{|c|}{$\begin{array}{l}\text { Mean difference in } \\
\text { FEV }_{1} / \mathrm{FVC} \\
(6-24 \text { years })\end{array}$} \\
\hline & & (SE) & $P$ value & (SE) & $P$ value & (SE) & $P$ value & (SE) & P value \\
\hline $\begin{array}{l}\text { Ln } \\
\text { V'maxFRC at }\end{array}$ & $\begin{array}{l}190 \\
(525)\end{array}$ & $\begin{array}{c}0 \cdot 01 \\
(0 \cdot 015)\end{array}$ & 0.53 & $\begin{array}{l}-0.002 \\
(0.029)\end{array}$ & 0.49 & $\begin{array}{l}0 \cdot 08 \\
(0 \cdot 03)\end{array}$ & 0.008 & $\begin{array}{r}0 \cdot 015 \\
(0 \cdot 004)\end{array}$ & $<0.001$ \\
\hline 1 month & & & & & & & & & \\
\hline $\begin{array}{l}\text { Maternal } \\
\text { smoking in } \\
\text { pregnancy }\end{array}$ & $\begin{array}{l}199 \\
(549)\end{array}$ & $\begin{array}{l}-0 \cdot 077 \\
(0 \cdot 038)\end{array}$ & 0.045 & $\begin{array}{l}-0 \cdot 109 \\
(0 \cdot 062)\end{array}$ & 0.087 & $\begin{array}{l}-0.067 \\
(0.064)\end{array}$ & $0 \cdot 293$ & $\begin{array}{l}-0 \cdot 0021 \\
(0 \cdot 008)\end{array}$ & $0 \cdot 86$ \\
\hline $\begin{array}{l}\text { Maternal } \\
\text { asthma }\end{array}$ & $\begin{array}{l}200 \\
(549)\end{array}$ & $\begin{array}{l}-0.099 \\
(0.045)\end{array}$ & 0.03 & $\begin{array}{l}-0.078 \\
(0 \cdot 048)\end{array}$ & $0 \cdot 1$ & $\begin{array}{l}-0.037 \\
0.074\end{array}$ & 0.62 & $\begin{array}{l}-0 \cdot 012 \\
(0 \cdot 009)\end{array}$ & $0 \cdot 21$ \\
\hline Breastfed $\mathrm{x}$ & 147 & 0.037 & 0.39 & -0.009 & 0.88 & 0.065 & 0.39 & 0.015 & $0 \cdot 1$ \\
\hline 3months & (454) & $(0 \cdot 04)$ & & $(0.065)$ & & $(0.076)$ & & $(0 \cdot 01)$ & \\
\hline Early atopy & $\begin{array}{l}150 \\
(430)\end{array}$ & $\begin{array}{l}-0 \cdot 138 \\
(0 \cdot 055)\end{array}$ & 0.019 & $\begin{array}{l}-0 \cdot 062 \\
(0 \cdot 084)\end{array}$ & 0.47 & $\begin{array}{r}-0 \cdot 25 \\
(0.086)\end{array}$ & 0.004 & $\begin{array}{r}-0.023 \\
(0 \cdot 011)\end{array}$ & 0.036 \\
\hline Asthma ever & $\begin{array}{l}145 \\
(450)\end{array}$ & $\begin{array}{l}0.048 \\
(0.052)\end{array}$ & $0 \cdot 36$ & $\begin{array}{l}0.047 \\
(0.035)\end{array}$ & $0 \cdot 18$ & $\begin{array}{l}-0 \cdot 11 \\
(0 \cdot 075)\end{array}$ & $0 \cdot 14$ & $\begin{array}{l}-0 \cdot 031 \\
(0.009)\end{array}$ & 0.001 \\
\hline $\begin{array}{l}\text { Tobacco } \\
\text { smoker at } 24\end{array}$ & $\begin{array}{c}147 \\
(452)\end{array}$ & $\begin{array}{l}0.015 \\
(0 \cdot 04)\end{array}$ & 0.73 & $\begin{array}{l}0 \cdot 114 \\
(0 \cdot 076)\end{array}$ & $0 \cdot 17$ & $\begin{array}{l}-0 \cdot 019 \\
(0 \cdot 087)\end{array}$ & 0.83 & $\begin{array}{l}-0 \cdot 02 \\
(0 \cdot 011)\end{array}$ & 0.074 \\
\hline
\end{tabular}

years

Univariate analysis using linear mixed model. Mean difference in lung function associated with each factor, assessed longitudinally from 6-24 years. Time dependent variables age and height at each assessment and the time-independent variable of sex were included in the model. V'maxFRC $\mathrm{ml} / \mathrm{s}$ at 1 month was $\log$ transformed and then adjusted for infant length. Bold font indicates $\mathrm{p}<0 \cdot 05$. 
Table 3: Factors associated with lung function longitudinally from 6 to 24 years: multivariate analysis

\begin{tabular}{|c|c|c|c|c|c|c|}
\hline & \multicolumn{2}{|c|}{$\begin{array}{r}\text { Mean difference } \\
\text { FEV1 (L) 6-24 yrs } \\
\text { n=150 }\end{array}$} & \multicolumn{2}{|c|}{$\begin{array}{c}\text { Mean difference } \\
\text { FEF25-75\% 6-24 yrs } \\
\text { n=146 }\end{array}$} & \multicolumn{2}{|c|}{$\begin{array}{l}\text { Mean difference } \\
\text { FEV1/FVC 6-24 yrs } \\
\text { n=110 }\end{array}$} \\
\hline & (SE) & $P$ value & (SE) & P value & (SE) & $P$ value \\
\hline Maternal smoking & $\begin{array}{l}-0 \cdot 061 \\
(0 \cdot 041)\end{array}$ & $0 \cdot 148$ & - & - & - & - \\
\hline Maternal asthma & $\begin{array}{l}0 \cdot 084 \\
(0 \cdot 05)\end{array}$ & $0 \cdot 1$ & - & - & - & - \\
\hline V'maxFRC at 1 month & - & - & $\begin{array}{r}0.09 \\
(0 \cdot 033)\end{array}$ & 0.008 & $\begin{array}{l}0.035 \\
(0.039)\end{array}$ & $0 \cdot 36$ \\
\hline Early atopy & $\begin{array}{r}-0 \cdot 125 \\
(0.05)\end{array}$ & $0 \cdot 015$ & $\begin{array}{r}0.218 \\
(0.087)\end{array}$ & $0 . \cdot 013$ & $\begin{array}{r}-0.024 \\
(0.095)\end{array}$ & $0 \cdot 013$ \\
\hline Asthma ever & - & - & - & - & $\begin{array}{l}-0.039 \\
(0.085)\end{array}$ & 0.65 \\
\hline
\end{tabular}

Multi-variate analysis using linear mixed model. Mean difference in lung function associated with each factor, assessed longitudinally from 6-24 years. Time dependent variables age and height at each assessment and the time-independent variable of sex were included in the model. V'maxFRC was log transformed and then adjusted for length. Only variables with $\mathrm{p}<0.05$ in the univariate model were included in the multivariate model. Bold font indicates $\mathrm{p}<0 \cdot 05$ 
Table 4. Odds ratio for developing outcome at each assessment if V'maxFRC below the median at 1 month of age

\begin{tabular}{|c|c|c|c|c|c|c|c|c|}
\hline & 6 year & & 11 years & & 18 years & & 24 years & \\
\hline & $\begin{array}{r}\text { OR } \\
(95 \% \mathrm{CI})\end{array}$ & $P$ value & $\begin{array}{c}\text { OR } \\
(95 \% \mathrm{CI})\end{array}$ & $P$ value & $\begin{array}{c}\text { OR } \\
(95 \% \mathrm{CI})\end{array}$ & $P$ value & $\begin{array}{c}\text { OR } \\
(95 \% \mathrm{CI})\end{array}$ & $P$ value \\
\hline $\begin{array}{l}\text { Recent } \\
\text { Wheeze }\end{array}$ & $\begin{array}{c}8.05 \\
(1.5-10.4)\end{array}$ & 0.004 & $\begin{array}{c}4 \cdot 5 \\
(1 \cdot 1-5 \cdot 4)\end{array}$ & 0.033 & $\begin{array}{c}3 \cdot 1 \\
(0 \cdot 92-4 \cdot 2)\end{array}$ & $0 \cdot 08$ & $\begin{array}{c}2.0 \\
(1 \cdot 09-4)\end{array}$ & 0.047 \\
\hline $\begin{array}{l}\text { Current } \\
\text { Asthma }^{\#}\end{array}$ & $\begin{array}{c}1 \cdot 6 \\
(0 \cdot 7-3 \cdot 7)\end{array}$ & $0 \cdot 27$ & $\begin{array}{c}1 \cdot 8 \\
(0 \cdot 8-4)\end{array}$ & $0 \cdot 16$ & $\begin{array}{c}3 \cdot 5 \\
(1 \cdot 2-10 \cdot 5)\end{array}$ & $0 \cdot 023$ & $\begin{array}{c}4.05 \\
(1.4-11)\end{array}$ & 0.006 \\
\hline
\end{tabular}

\footnotetext{
*Wheeze reported in the 12 months prior to assessment

\#Physician diagnosis of asthma with symptoms or medications in the 12 months prior to assessment
} 
Figure 1 Lung function at 6,11,18 and 24 years in those with V'maxFRC above and below the median at 1 month of age
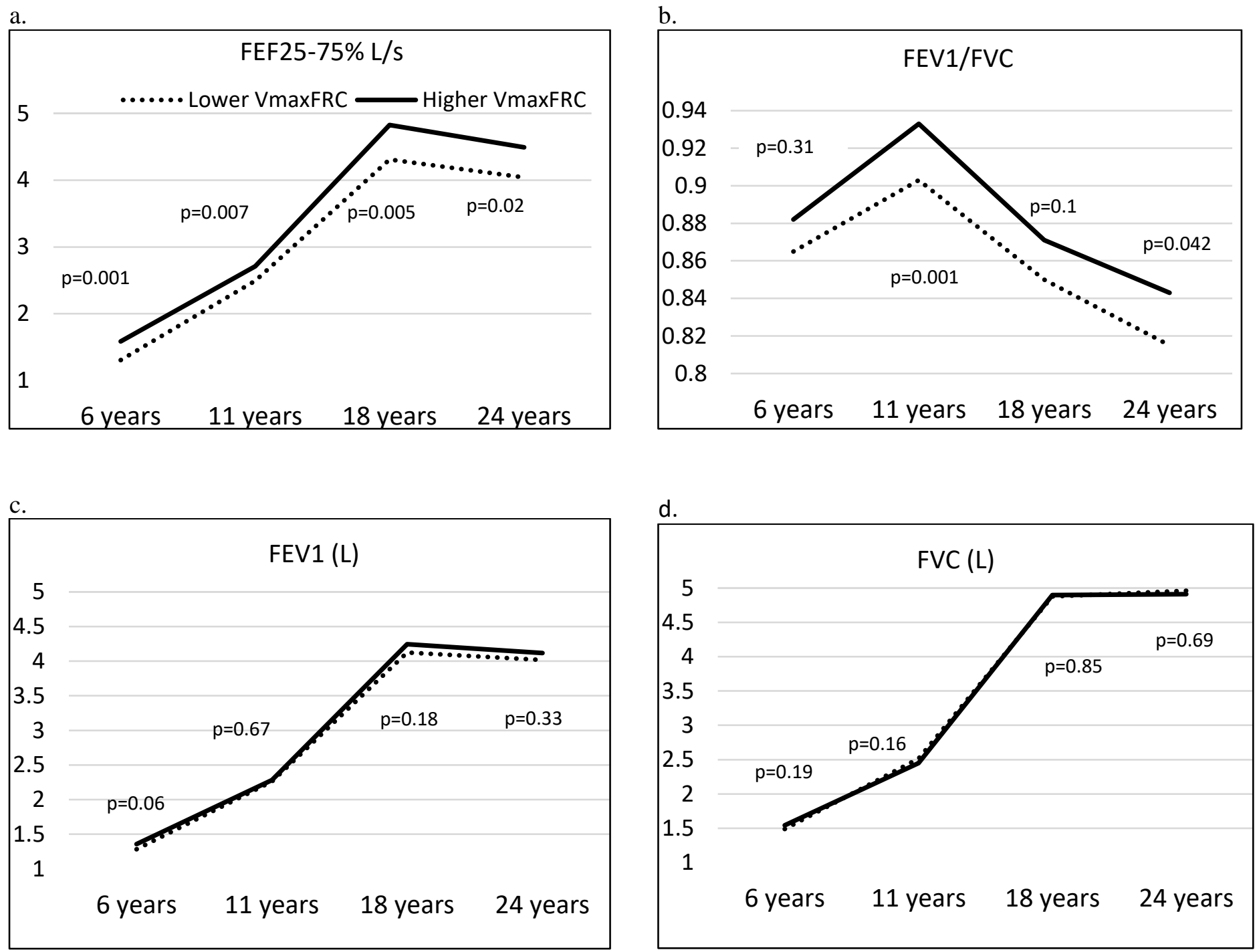
Panel a. FEF 25-75\%; panel b. FEV1/FVC; panel c. FEV1; panel d. FVC.

Univariate general linear model with $V$ 'maxFRC at 1 month log transformed and then adjusted for length and gender. Dashed line $-V^{\prime}$ maxFRC $<$ median at 1 month of age, solid line $-V^{\prime}$ maxFRC $>$ median at 1 month of age.

Spirometry adjusted for gender, height and age at assessment and standardised to mean age and height at each assessment.

\section{References}

1. Quanjer PH, Stanojevic S, Cole TJ, Baur X, Hall GL, Culver BH, Enright PL, Hankinson JL, Ip MS, Zheng $J$ et al. Multi-ethnic reference values for spirometry for the 3-95-yr age range: the global lung function 2012 equations. Eur Respir J 2012; 40(6): 1324-43.

2. Bush A. COPD: a pediatric disease. Copd 2008; 5(1): 53-67.

3. Martinez FD. The origins of asthma and chronic obstructive pulmonary disease in early life. Proceedings of the American Thoracic Society 2009; 6(3): 272-7.

4. Henderson AJ. The child is father of the man: the importance of early life influences on lung development. Thorax 2014.

5. Stocks J, Sonnappa S. Early life influences on the development of chronic obstructive pulmonary disease. Therapeutic advances in respiratory disease 2013; 7(3): 161-73.

6. Le Souef PN. Pediatric origins of adult lung diseases. 4. Tobacco related lung diseases begin in childhood. Thorax 2000; 55(12): 1063-7.

7. Stick S. Pediatric origins of adult lung disease. 1. The contribution of airway development to paediatric and adult lung disease. Thorax 2000; 55(7): 587-94.

8. Lange P, Celli B, Agustí A, Boje Jensen G, Divo M, Faner R, Guerra S, Marott JL, Martinez FD, Martinez-Camblor $\mathrm{P}$ et al. Lung-Function Trajectories Leading to Chronic Obstructive Pulmonary Disease. N Eng J Med 2015; 373(2): 111-22.

9. Stern DA, Morgan WJ, Wright AL, Guerra S, Martinez FD. Poor airway function in early infancy and lung function by age 22 years: a non-selective longitudinal cohort study. Lancet (London, England) 2007; 370(9589): 758-64.

10. Young S, Le Souef PN, Geelhoed GC, Stick SM, Turner KJ, Landau LI. The influence of a family history of asthma and parental smoking on airway responsiveness in early infancy. $N$ Eng J Med 1991; 324(17): 1168-73.

11. Sly PD, Tepper R, Henschen M, Gappa M, Stocks J. Tidal forced expirations. ERS/ATS Task Force on Standards for Infant Respiratory Function Testing. European Respiratory Society/American Thoracic Society. The Eur Respir J 2000; 16(4): 741-8.

12. Young S, Sherrill DL, Arnott J, Diepeveen D, LeSouef PN, Landau LI. Parental factors affecting respiratory function during the first year of life. Pediatr Pulmonol 2000; 29(5): 331-40. 
13. Miller MR, Hankinson J, Brusasco V, Burgos F, Casaburi R, Coates A, Crapo R, Enright P, Grinten CP, Gustafsson P. Standardisation of spirometry. Eur Respir J 2005; 26(2): 319-38.

14. Yan K, Salome C, Woolcock AJ. Rapid method for measurement of bronchial responsiveness. Thorax 1983; 38(10): 760-5.

15. de Meer G, Marks GB, de Jongste JC, Brunekreef B. Airway responsiveness to hypertonic saline: dose-response slope or PD15? Eur Respir J 2005; 25(1): 153-8.

16. Pepys J. Skin tests for immediate, type I, allergic reactions. Proc R Soc Med 1972; 65(3): 2712.

17. Skin prick testing for the diagnosis of allergic disease. A manual for practitioners https://www.allergy.org.au/images/stories/pospapers/ASCIA_SPT_Manual_November_2013.pdf. In: Allergy ASoCla, editor.: ASCIA skin prick testing working party; 2013.

18. Turner S, Fielding S, Mullane D, Cox DW, Goldblatt J, Landau L, Le Souef PN. A longitudinal study of lung function from 1 month to 18 years of age. Thorax 2014; 69(11): 1015-20.

19. Sont JK, Han J, van Krieken JM, Evertse CE, Hooijer R, Willems LN, Sterk PJ. Relationship between the inflammatory infiltrate in bronchial biopsy specimens and clinical severity of asthma in patients treated with inhaled steroids. Thorax. 1996 May;51(5):496-502.

20. Palmer LJ, Rye PJ, Gibson NA, Burton PR, Landau LI, Le Souef PN. Airway responsiveness in early infancy predicts asthma, lung function, and respiratory symptoms by school age. Am J Respir Crit Care Med 2001; 163(1): 37-42.

21. Lodrup Carlsen KC, Jaakkola JJ, Nafstad P, Carlsen KH. In utero exposure to cigarette smoking influences lung function at birth. Eur Respir J 1997; 10(8): 1774-9.

22. Hanrahan JP, Tager IB, Segal MR, Tosteson TD, Castile RG, Van Vunakis H, Weiss ST, Speizer FE. The effect of maternal smoking during pregnancy on early infant lung function. Am Rev Respir Dis 1992; 145(5): 1129-35.

23. Lange P, Parner J, Vestbo J, Schnohr P, Jensen G. A 15-year follow-up study of ventilatory function in adults with asthma. N Eng J Med 1998; 339(17): 1194-200.

24. Magnussen C, Ojeda FM, Rzayeva N, Zeller T, Sinning CR, Pfeiffer N, Beutel M, Blettner M, Lackner KJ, Blankenberg S et al. FEV1 and FVC predict all-cause mortality independent of cardiac function - Results from the population-based Gutenberg Health Study. Int J Cardiol 2017; 234: 64-8.

25. Owens L, Laing I, Zhang G, Le Souef P. Early sensitization is associated with reduced lung function from birth into adulthood. J Allergy Clin Immunol 2016; 137(5): 1605-7.

26. Shirtcliffe P, Marsh S, Travers J, Weatherall M, Beasley R. Childhood asthma and GOLDdefined chronic obstructive pulmonary disease. Intern Med J 2012; 42(1): 83-8.

27. ATS/ERS statement: raised volume forced expirations in infants: guidelines for current practice. Am J Respir Crit Care Med 2005; 172(11): 1463-71. 
28. Turner DJ, Stick SM, Lesouef KL, Sly PD, Lesouef PN. A new technique to generate and assess forced expiration from raised lung volume in infants. Am J Respir Crit Care Med 1995; 151(5): 144150. 